\title{
Prognostic value of the systemic immune-inflammation index in patients with breast cancer: a meta-analysis
}

\author{
Yantao Zhang, Yong Sun * (10) and Qiwen Zhang
}

\begin{abstract}
Background: Although previous studies have evaluated the prognostic role of the systemic immune-inflammation index (SII) in patients with breast cancer, the results were inconsistent. Therefore, in this context, we aimed to identify the prognostic and clinicopathological value of the SII in patients with breast cancer by performing a meta-analysis.

Methods: A literature search was using PubMed, Web of Science, EMBASE, and Cochrane Library databases for relevant articles, from their inception to May 12, 2020. The prognostic value of the SII in breast cancer was assessed by pooling the hazard ratios (HRs) with 95\% confidence intervals (Cls). The clinical outcomes included the overall survival (OS), disease-free survival (DFS), recurrence-free survival (RFS), and distant metastasis-free survival (DMFS). The methodological quality of all the included studies was evaluated using the Newcastle-Ottawa quality assessment scale. The odds ratios (ORs) with 95\% Cls were combined to evaluate the correlation between the SII and clinicopathological characteristics of patients with breast cancer. Publication bias was evaluated using the Begg funnel plot and the Egger linear regression test. All statistical analyses were performed using Stata software, version 12.0 (Stata Corporation, College Station, TX, USA). A $p$ value of $<0.05$ was considered statistically significant.
\end{abstract}

Results: Eight studies involving 2642 patients were included in the current meta-analysis. The combined data showed that patients with a high SIl had worse OS ( $H R=1.79,95 \% \mathrm{Cl} 1.33-2.42, \mathrm{p}<0.001)$, poorer DFS/RFS (HR $=1.79,95 \%$ $\mathrm{Cl} 1.31-2.46, \mathrm{p}<0.001)$, and inferior DMFS ( $H R=1.64,95 \% \mathrm{Cl} 1.32-2.03, \mathrm{p}<0.001)$ than patients with a low SII. In addition, a high SII was correlated with the presence of lymph node metastasis $(\mathrm{OR}=1.38,95 \% \mathrm{Cl} 1.12-1.69, \mathrm{p}=0.002)$, higher T stage $(\mathrm{OR}=1.49,95 \% \mathrm{Cl} 1.17-1.89, \mathrm{p}<0.001)$, advanced TNM stage $(\mathrm{OR}=1.37,95 \% \mathrm{Cl} 1.07-1.77, \mathrm{p}=0.014)$, and higher histological grade $(\mathrm{OR}=3.71,95 \% \mathrm{Cl} 1.00-13.73, \mathrm{p}=0.049)$. However, there was no significant association between the $\mathrm{SII}$ and the pathological type $(\mathrm{OR}=0.82,95 \% \mathrm{Cl} 0.55-1.23, \mathrm{p}=0.345)$ or lymphatic invasion $(\mathrm{OR}=1.30,95 \% \mathrm{Cl} 0.82-2.08, \mathrm{p}=0.266)$.

Conclusions: The results of our meta-analysis suggest that an elevated SII predicts poor survival outcomes and is associated with clinicopathological features that indicate tumor progression of breast cancer.

Keywords: Breast cancer, Meta-analysis, Systemic immune-inflammation index, Prognosis, Tumor microenvironment

\section{Background}

Breast cancer is the most common malignancy and the leading cause of cancer-related deaths in women

*Correspondence: Iwzyt123@163.com

Department of Two Gland Surgery, Jinan People's Hospital Affiliated

to Shandong First Medical University, Jinan, Shandong 271100, China worldwide [1]. In 2018, approximately 2,088,849 new cases of breast cancer and 626,679 deaths occurred worldwide [1]. Over the past several decades, the mortality due to breast cancer has decreased in Europe and in the United States because of early diagnosis and systemic treatments [2]. For patients with breast cancer with local and metastatic disease, the treatment approaches include 
surgery, radiotherapy, and systematic treatment with chemotherapy, endocrine therapy, and targeted therapy, or a combination of these [3]. However, the clinical outcomes of patients with breast cancer remain unsatisfactory owing to a lack of effective prognostic factors. Therefore, novel and reliable prognostic parameters need to be identified for designing personalized treatment regimens and for improving the survival of patients with breast cancer.

Tumor environment and inflammation play important roles in tumor development [4]. The components of the tumor microenvironment include the response cells, such as neutrophils, monocytes, lymphocytes, platelets, and cytokines. Several inflammatory cell parameters, including the neutrophil-lymphocyte ratio, plateletlymphocyte ratio, C-reactive protein/albumin ratio, and systemic immune-inflammation index (SII), are derived using these meditators. The SII is an index that is calculated on the basis of the platelet, neutrophil, and lymphocyte counts. The SII has been used to evaluate the pretreatment balance between inflammatory factors and immune status of patients with cancer [5-8]. The SII is associated with the prognosis of patients with breast cancer, although the results are controversial [9-16]. Therefore, we performed the current meta-analysis to identify the prognostic impact of the SII in patients with breast cancer by aggregating all available data.

\section{Materials and methods}

\section{Search strategy}

The current meta-analysis was conducted according to the Preferred Reporting Items for Systematic Reviews and Meta-Analyses Statement [17]. A literature search was using PubMed, Web of Science, EMBASE, and Cochrane Library databases for relevant articles, from their inception to May 12, 2020. The following search terms were used: (systemic immune-inflammatory index or SII or systemic-immune-inflammation index or systemic immune-inflammation index) and (breast carcinoma or breast tumor or Breast Cancer or Breast Tumors or Cancer of Breast or Cancer of the Breast or Human Mammary Carcinoma or Mammary Carcinoma, Human or Mammary Neoplasm, Human or Mammary Neoplasms, Human or Neoplasms, Breast or Tumors, Breast or Breast Neoplasm or Breast Tumor or Cancer, Breast or Carcinoma, Human Mammary or Carcinomas, Human Mammary or Human Mammary Carcinomas or Human Mammary Neoplasm or Human Mammary Neoplasms or Mammary Carcinomas, Human or Neoplasm, Breast or Neoplasm, Human Mammary or Neoplasms, Human Mammary or Tumor, Breast). The references of the searched articles were also manually checked for additional relevant records. The language of publication was restricted to English. There were no restrictions on the study design (prospective or retrospective), location, or ethnicity. The current meta-analysis collected data from previously published studies; therefore, approval was not required from the ethical committee or medical institutional board.

\section{Inclusion and exclusion criteria}

The inclusion criteria for eligible studies were as follows: (1) all patients were diagnosed with breast cancer; (2) studies reported the association between the SII and prognosis of patients with breast cancer; (3) a cutoff value was given for defining a high and a low SII; (4) the hazard ratios (HRs) with 95\% confidence intervals (CIs) for survival outcomes were reported or sufficient data were given for calculating the HRs with 95\% CIs. The following studies were excluded: (1) letters, reviews, and case reports; (2) duplicate studies; (3) studies with insufficient data; and (4) animal studies.

\section{Data extraction and quality assessment}

Two independent investigators (Y.Z. and Y.S.) extracted the data from eligible studies by using a standardized form. Any disagreements were resolved via discussion with a third investigator (Q.Z.). The extracted information included the name of the first author, year of publication, country of study origin, study duration, molecular stratification of breast cancer, sample size, median age, clinical stage, ethnicity, treatment methods, SII cutoff value, method for cutoff determination, follow-up, survival outcomes, and HRs with $95 \%$ CIs. The clinical outcomes included the overall survival (OS), disease-free survival (DFS), recurrence-free survival (RFS), and distant metastasis-free survival (DMFS). The methodological quality of all the included studies was evaluated by using the Newcastle-Ottawa quality assessment scale (NOS) [18]. The NOS assesses the quality of the included studies by using a score of 0 to 9 points. Studies with a NOS score of $\geq 6$ points were regarded as high-quality studies.

\section{Statistical analysis}

The prognostic value of the SII in patients with breast cancer was assessed by pooling the HRs and $95 \%$ CIs. The odds ratios (ORs) with 95\% CIs were combined to evaluate the correlation between the SII and clinicopathological characteristics of patients with breast cancer. The heterogeneity among studies was evaluated using the Cochran Q test [19] and the Higgins $I^{2}$ statistics [20]. Significant heterogeneity was defined as $\mathrm{p}<0.10$ and/or $I^{2}>50 \%$, and then, a random-effects model was applied for pooling the data. Otherwise, a fixed-effects model was applied. Subgroup analysis-stratified by the 
molecular stratification, cutoff value of the SII, method for cutoff determination, and treatment-was performed to explore the sources of heterogeneity. Publication bias was evaluated using the Begg funnel plot [21] and the Egger linear regression test [22]. All statistical analyses were performed using Stata software, version 12.0 (Stata Corporation, College Station, TX, USA). A p-value of $<0.05$ was considered statistically significant.

\section{Results}

\section{Search results and study characteristics}

A total of 109 studies were identified after the initial search of the databases, and then, 50 duplicate records were removed. After screening the title and/or the abstract, 46 studies were eliminated on the basis of the inclusion criteria. Then, 13 full-text articles were evaluated for eligibility [9-16, 23-27]. A total of 5 studies were removed owing to the following reasons: 4 studies [23-25, 27] did not provide sufficient data for the current meta-analysis, and 1 study [26] included patients with different cancers, rather than breast cancer only. Finally, 8 studies [9-16] involving 2642 patients were included in the current meta-analysis. A flowchart of the literature search is shown in Fig. 1. The general characteristics of the enrolled studies are summarized in Table 1 . The included studies were published from 2019 to 2020 and were mainly conducted in 2 countries, including 1 in Italy [9] and 7 in China [10-16]. The total sample size was

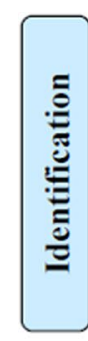

Records identified through database searching

$(\mathrm{n}=109)$

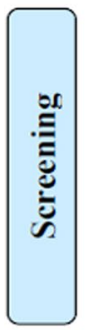

Records after duplicates removed $(\mathrm{n}=59)$

Additional records identified through other sources $(\mathrm{n}=0)$
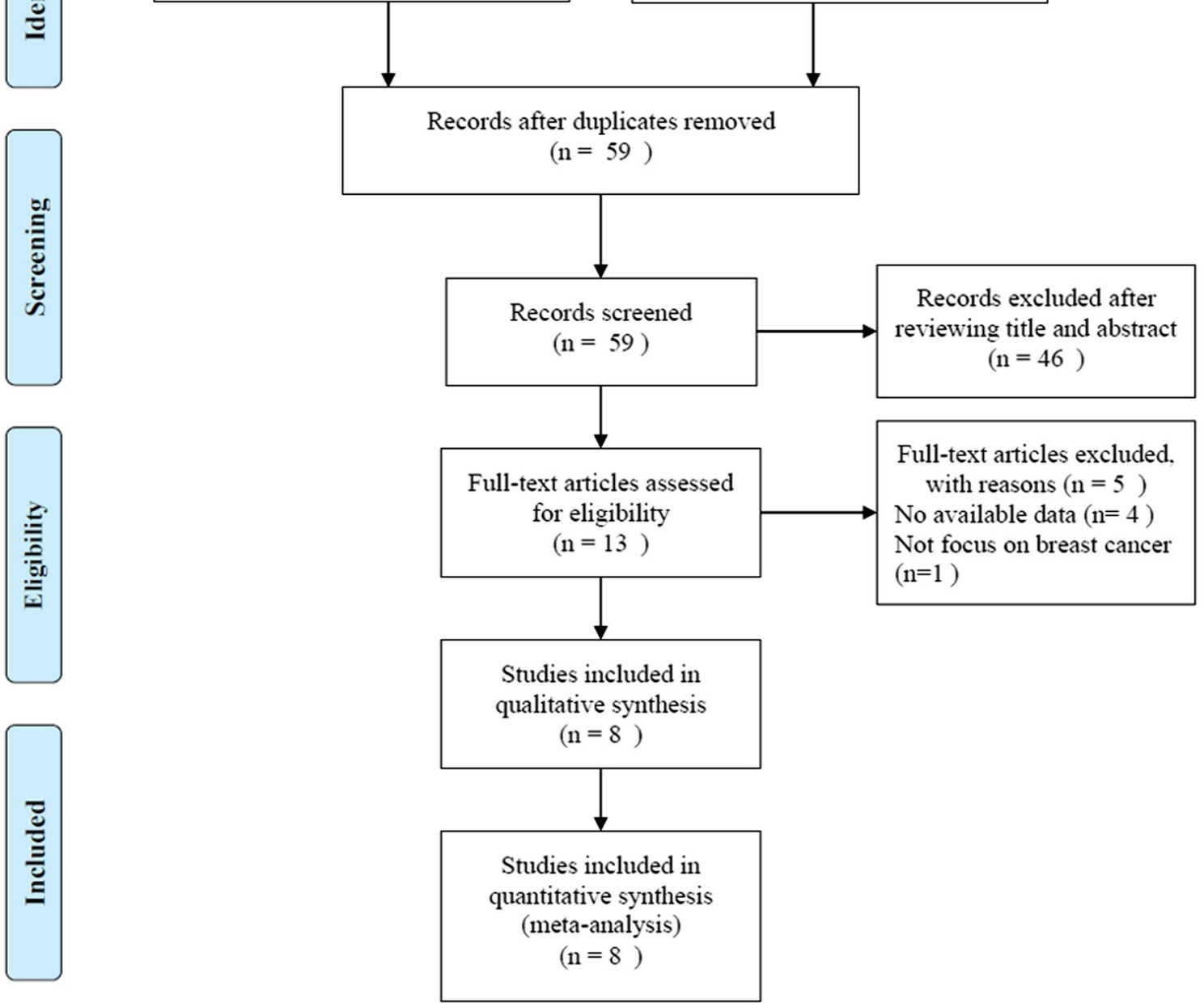

Full-text articles excluded. with reasons $(\mathrm{n}=5)$ No available data $(n=4)$ Not focus on breast cancer $(\mathrm{n}=1)$

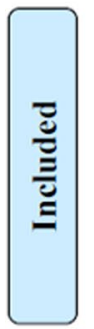

Fig. 1 Schematic flow diagram for selection of included studies 


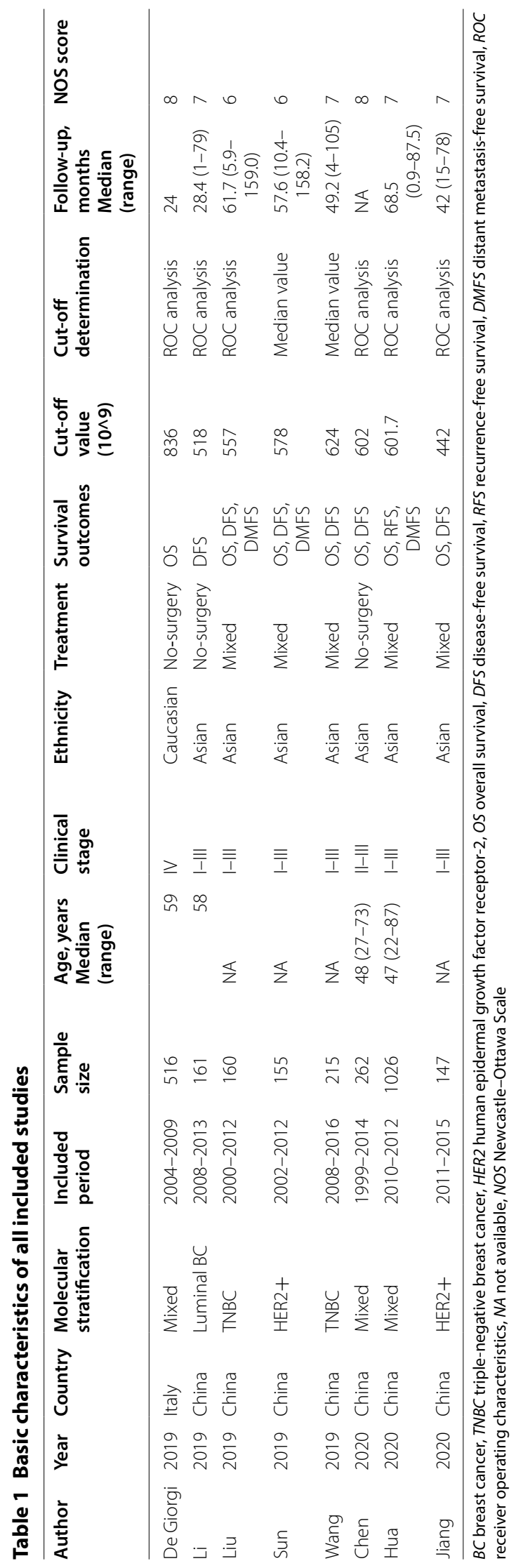




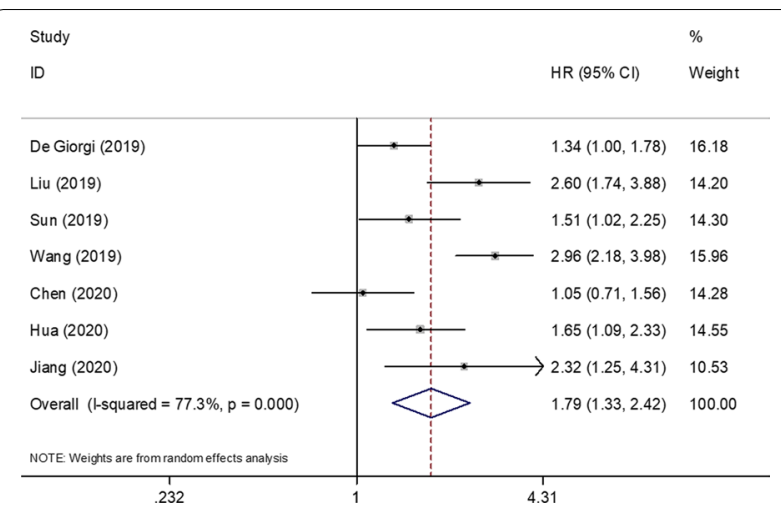

Fig. 2 Forest plot of the correlation between SII and overall survival in patients with breast cancer

2642 patients, ranging from 147 to 1026 patients. Seven studies reported the prognostic value of the SII considering OS [9, 11-16], 7 studies provided data on the association between the SII and DFS/RFS [10-16], and 3 studies reported the correlation between the SII and DMFS [11, 12, 16]. The cutoff values of the SII ranged from 422 to 836 in the included studies. Considering the quality assessment of the eligible studies, all the studies had a NOS score of $\geq 6$ and the median value was 7 , indicating that all the included studies were high-quality studies.

\section{Association between the SII and OS of patients with breast cancer}

The data regarding the association between the SII and OS were available in 7 studies with 2481 patients [9, 11-16]. As shown in Fig. 2, the pooled HRs and 95\% CIs revealed that patients with a high SII had worse OS $(\mathrm{HR}=1.79,95 \% \mathrm{CI} 1.33-2.42, \mathrm{p}<0.001)$ than patients with a low SII. A random-effects model was used because of significant heterogeneity $\left(I^{2}=77.3 \%, \mathrm{p}<0.001\right.$; Fig. 2; Table 2). Subgroup analysis of OS was conducted on the basis of the molecular stratification, cutoff value of the SII, method for cutoff determination, and treatment. The subgroup analysis showed that an elevated SII was associated with poor OS of patients with triple-negative breast cancer (TNBC; HR $=2.82,95 \%$ CI $2.22-3.59, \mathrm{p}<0.001$ ), patients with breast cancer that was positive for human epidermal growth factor receptor-2 $(\mathrm{HR}=1.71,95 \%$ CI 1.23-2.39, $\mathrm{p}=0.002$ ), and patients with mixed molecular stratification $(\mathrm{HR}=1.33,95 \% \mathrm{CI} 1.09-1.63, \mathrm{p}=0.005$; Table 2). Considering the cut-off value of the SII, an SII cut-off value of $\leq 600 \quad(\mathrm{HR}=2.03,95 \% \mathrm{CI} 1.57-2.62$, $\mathrm{p}<0.001)$ and an SII cut-off value of $>600(\mathrm{HR}=1.63$, 95\% CI 1.04-2.56, $\mathrm{p}=0.033$ ) showed prognostic value for poor OS. Regarding the cut-off determination methods, both receiver operating characteristic curve analysis
$(\mathrm{HR}=1.65,95 \% \mathrm{CI} 1.20-2.26, \mathrm{p}=0.002)$ and the median value $(\mathrm{HR}=2.14,95 \% \mathrm{CI} 1.11-4.14, \mathrm{p}=0.024)$ to determine the cut-off value were correlated with poor OS. Considering the treatment, a high SII showed a prognostic value for worse OS of patients receiving mixed treatments $(\mathrm{HR}=2.15,95 \% \mathrm{CI} 1.61-2.86, \mathrm{p}<0.001$; Table 2$)$.

\section{Association between the SII and DFS/RFS of patients with breast cancer}

A total of 7 studies consisting of 2126 patients [10-16] investigated the association between the SII and DFS/ RFS. Owing to significant heterogeneity $\left(I^{2}=66.0 \%\right.$, $\mathrm{p}=0.007$ ), a random-effects model was applied (Fig. 3; Table 2). The combined data showed that an elevated SII was correlated with poor DFS/RFS of patients with breast cancer $(H R=1.79,95 \%$ CI 1.31-2.46, $\mathrm{p}<0.001$; Fig. 3). Subgroup analysis stratified by molecular stratification showed that a high SII was associated with poor DFS/RFS of patients with luminal breast cancer $(\mathrm{HR}=6.04,95 \% \mathrm{CI} 1.82-19.98, \mathrm{p}=0.003)$ and patients with TNBC $(\mathrm{HR}=2.03,95 \%$ CI 1.06-3.88, $\mathrm{p}=0.033$; Table 2). In addition, an SII cut-off value of $\leq 600$ $(\mathrm{HR}=1.92, \quad 95 \%$ CI $1.20-3.08, \quad \mathrm{p}=0.006) \quad$ and $>600$ $(\mathrm{HR}=1.70,95 \% \mathrm{CI} 1.01-2.88, \mathrm{p}=0.047)$ predicted poor DFS/RFS. A high SII was associated with poor DFS/RFS of patients receiving mixed treatments $(\mathrm{HR}=1.8,95 \%$ CI 1.36-2.42, $\mathrm{p}<0.001$; Table 2).

\section{Association between the SII and DMFS of patients with breast cancer}

Three studies involving 1341 patients $[11,12,16]$ provided data regarding the prognostic impact of the SII for DMFS. The pooled HR and 95\% CI were 1.64 and $1.32-2.03$, respectively $(\mathrm{p}<0.001)$, with no significant heterogeneity $\left(I^{2}=0 \%, \mathrm{p}=0.590\right.$; Fig. 4; Table 2). Owing to the limited sample size, subgroup analysis was not performed for DMFS.

\section{Association between the SII and clinicopathological features of patients with breast cancer}

The relationship between the SII and clinicopathological characteristics was analyzed by using data from 6 studies with 1966 patients [10, 12-16]. Six clinicopathological factors were investigated, including lymph node metastasis (presence vs. absence), $\mathrm{T}$ stage (T2-T4 vs. T1), TNM stage (II-III vs. 0-I), histological grade (G3 vs. G1-G2), pathological type (intralobular carcinoma vs. intraductal carcinoma), and lymphatic invasion (presence vs. absence). The combined ORs and 95\% CIs indicated that a high SII was correlated with the presence of lymph node metastasis $(\mathrm{OR}=1.38,95 \%$ 
Table 2 Stratified analysis of pooled HR of breast cancer patients with SII on OS, DFS, RFS, and DMFS

\begin{tabular}{|c|c|c|c|c|c|c|c|}
\hline \multirow[t]{2}{*}{ Subgroup analysis } & \multirow[t]{2}{*}{ No. of studies } & \multirow[t]{2}{*}{ No. of patients } & \multirow[t]{2}{*}{$\mathrm{HR}(95 \% \mathrm{Cl})$} & \multirow[t]{2}{*}{$\mathbf{p}$} & \multirow[t]{2}{*}{ Effects model } & \multicolumn{2}{|c|}{ Heterogeneity } \\
\hline & & & & & & $I^{2}(\%)$ & $\mathbf{p}$ \\
\hline \multicolumn{8}{|l|}{ OS } \\
\hline Total & 7 & 2481 & $1.79(1.33-2.42)$ & $<0.001$ & Random & 77.3 & $<0.001$ \\
\hline \multicolumn{8}{|c|}{ Molecular stratification } \\
\hline Mixed & 3 & 1804 & $1.33(1.09-1.63)$ & 0.005 & Fixed & 21.9 & 0.278 \\
\hline TNBC & 2 & 375 & $2.82(2.22-3.59)$ & $<0.001$ & Fixed & 0 & 0.612 \\
\hline HER2+ & 2 & 302 & $1.71(1.23-2.39)$ & 0.002 & Fixed & 23.9 & 0.252 \\
\hline \multicolumn{8}{|l|}{ Cut-off value of SII } \\
\hline$\leq 600$ & 3 & 462 & $2.03(1.57-2.62)$ & $<0.001$ & Fixed & 47.3 & 0.150 \\
\hline$>600$ & 4 & 2019 & $1.63(1.04-2.56)$ & 0.033 & Random & 85.9 & $<0.001$ \\
\hline \multicolumn{8}{|c|}{ Method for cut-off determination } \\
\hline ROC analysis & 5 & 2111 & $1.65(1.20-2.26)$ & 0.002 & Random & 68.7 & 0.012 \\
\hline Median value & 2 & 370 & $2.14(1.11-4.14)$ & 0.024 & Random & 85.8 & 0.008 \\
\hline \multicolumn{8}{|l|}{ Treatment } \\
\hline Mixed & 5 & 1703 & $2.15(1.61-2.86)$ & $<0.001$ & Random & 60.5 & 0.038 \\
\hline No-surgery & 2 & 778 & $1.23(0.98-1.56)$ & 0.080 & Fixed & 0 & 0.330 \\
\hline \multicolumn{8}{|l|}{ DFS/RFS } \\
\hline Total & 7 & 2126 & $1.79(1.31-2.46)$ & $<0.001$ & Random & 66.0 & 0.007 \\
\hline \multicolumn{8}{|c|}{ Molecular stratification } \\
\hline Mixed & 2 & 1288 & $1.34(0.89-2.01)$ & 0.160 & Random & 56.6 & 0.129 \\
\hline Luminal BC & 1 & 161 & $6.04(1.82-19.98)$ & 0.003 & - & - & - \\
\hline TNBC & 2 & 375 & $2.03(1.06-3.88)$ & 0.033 & Random & 81.0 & 0.022 \\
\hline HER2+ & 2 & 302 & $1.94(0.83-4.56)$ & 0.128 & Random & 52.0 & 0.149 \\
\hline \multicolumn{8}{|l|}{ Cut-off value of SII } \\
\hline$\leq 600$ & 4 & 623 & $1.92(1.20-3.08)$ & 0.006 & Random & 57.2 & 0.072 \\
\hline$>600$ & 3 & 1503 & $1.70(1.01-2.88)$ & 0.047 & Random & 81.1 & 0.005 \\
\hline \multicolumn{8}{|c|}{ Method for cut-off determination } \\
\hline ROC analysis & 5 & 1756 & $1.68(1.14-2.47)$ & 0.008 & Random & 60.7 & 0.038 \\
\hline Median value & 2 & 370 & $2.02(1.05-3.89)$ & 0.035 & Random & 81.5 & 0.020 \\
\hline \multicolumn{8}{|l|}{ Treatment } \\
\hline Mixed & 5 & 1703 & $1.82(1.36-2.42)$ & $<0.001$ & Random & 52.5 & 0.078 \\
\hline No-surgery & 2 & 423 & $2.31(0.43-12.43)$ & 0.328 & Random & 86.1 & 0.007 \\
\hline \multicolumn{8}{|l|}{ DMFS } \\
\hline Total & 3 & 1341 & $1.64(1.32-2.03)$ & $<0.001$ & Fixed & 0 & 0.590 \\
\hline
\end{tabular}

CI1.12-1.69, $\mathrm{p}=0.002)$, higher $\mathrm{T}$ stage $(\mathrm{OR}=1.49$, 95\% CI 1.17-1.89, p $<0.001)$, advanced TNM stage $(\mathrm{OR}=1.37,95 \% \mathrm{CI} 1.07-1.77, \mathrm{p}=0.014)$, and higher histological grade $(\mathrm{OR}=3.71,95 \%$ CI 1.00-13.73, $\mathrm{p}=0.049$; Fig. 5; Table 3). However, there was no significant association between the SII and pathological type $(\mathrm{OR}=0.82,95 \%$ CI $0.55-1.23, \mathrm{p}=0.345)$ or lymphatic invasion $(\mathrm{OR}=1.30,95 \% \mathrm{CI} 0.82-2.08, \mathrm{p}=0.266$; Fig. 5; Table 3).

\section{Publication bias}

The Begg funnel plot and the Egger test were conducted to evaluate potential publication bias for OS, DFS/RFS, and DMFS analysis. For OS, the test results suggested that the potential publication bias was negative $(\mathrm{p}=0.881$ on the Begg test, and $\mathrm{p}=0.981$ on the Egger test; Fig. 6). Similarly, there was no significant publication bias for DFS/RFS ( $\mathrm{p}=0.548$ on the Begg test, and $\mathrm{p}=0.128$ on 


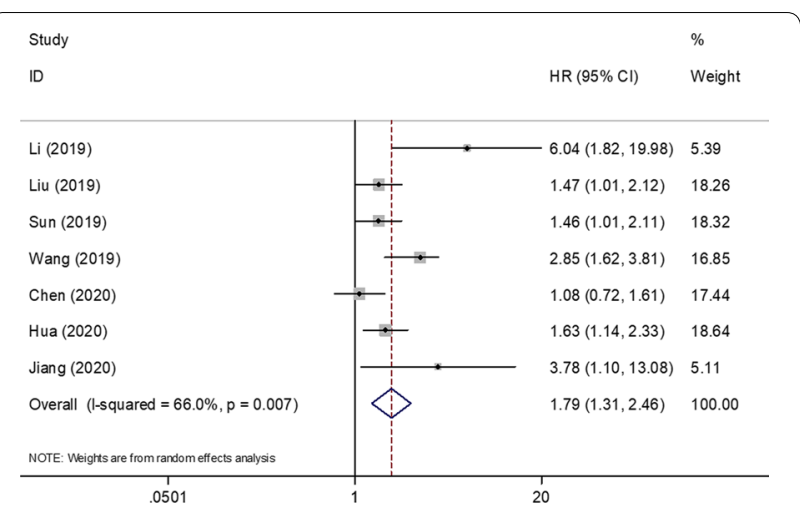

Fig. 3 Forest plot of the correlation between SII and disease-free survival/recurrence-free survival in patients with breast cancer

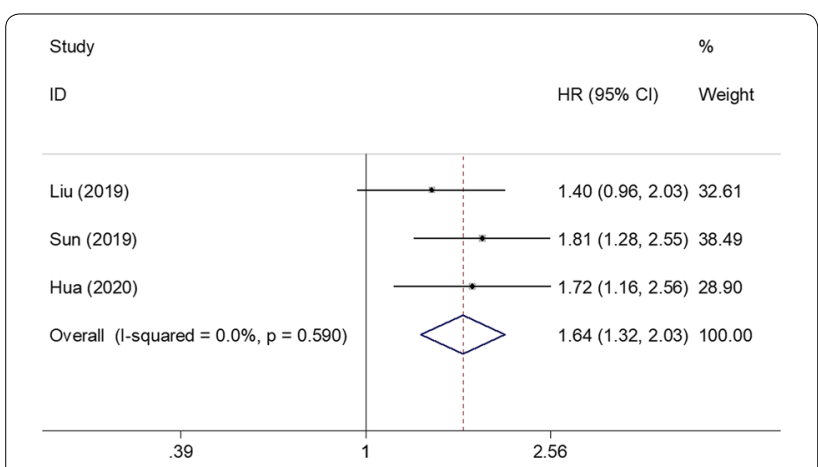

Fig. 4 Forest plot of the correlation between SII and distant metastasis-free survival in patients with breast cancer

the Egger test) or DMFS ( $\mathrm{p}=0.602$ on the Begg test, and $\mathrm{p}=0.785$ on the Egger test; Fig. 6 ).

\section{Discussion}

In the current meta-analysis, we evaluated the prognostic influence of the SII in patients with breast cancer. Our results showed that the SII was associated with worse OS, DFS/RFS, and DMFS. Moreover, the prognostic effect of the SII remained consistent for patients with TNBC as well as when the cutoff value of the SII was $\leq 600$. We also found that a high SII was associated with the clinical characteristics that indicated tumor progression and high malignancy, including the presence of lymph node metastasis, a higher T stage, advanced TNM stage, and higher histological grade. As the SII is a blood-derived parameter and is easily available, it is an optimal tool for aiding in the prognostication of patients with breast cancer. To the best of our knowledge, the present study is the first meta-analysis to evaluate the prognostic and clinicopathological value of the SII in patients with breast cancer.

The SII is calculated by using the following formula: neutrophil count $\times$ platelet count/lymphocyte count; the SII was developed as a prognostic factor for determining the survival outcomes of patients with various cancers in clinical practice [28-34]. As the SII is an index of the combination of neutrophil, platelet, and lymphocyte counts, a high SII could be attributed to the changes in the counts of these cells. Neutrophils can exert tumorpromoting activity by secreting a variety of inflammatory mediators, including vascular endothelial growth factor, interleukin (IL)-6, IL-10, and IL-22 [35]. Platelets can protect cancer cells from lysis by natural killer cells [36] and promote cancer cell arrest in the endothelium, supporting the formation of secondary lesions [37]. In contrast, lymphocytes are involved in cancer immunesurveillance to inhibit cancer progression [38]. Therefore, low lymphocyte counts may result in inadequate immunological reactions in patients with cancer [39].

The prognostic effect of the SII has been studied in many human tumors by using a meta-analysis approach [40-43]. A comprehensive meta-analysis containing 15 articles showed that an SII greater than the cutoff predicted poor OS in various cancers [40]. Moreover, another meta-analysis including 9 studies with 2441 patients revealed that an elevated pretreatment SII indicated significantly poorer OS, DFS/progression-free survival, and cancer-specific survival of patients with non-small cell lung cancer [42]. A recent meta-analysis published in 2020 demonstrated that an elevated SII was a poor prognostic factor for patients with hepatocellular carcinoma [43]. The results of the current meta-analysis extend the prognostic role of the SII for breast cancer. Therefore, we recommend that the SII be used to predict the prognosis of patients with breast cancer.

The current meta-analysis has several limitations. First, significant heterogeneity was detected even though we selected a random-effects model for calculation. Second, most eligible studies were from China; therefore, the results may be more relevant to Chinese patients. The prognostic value of the SII for patients of other nationalities still needs to be verified. Third, the cutoff value of the 


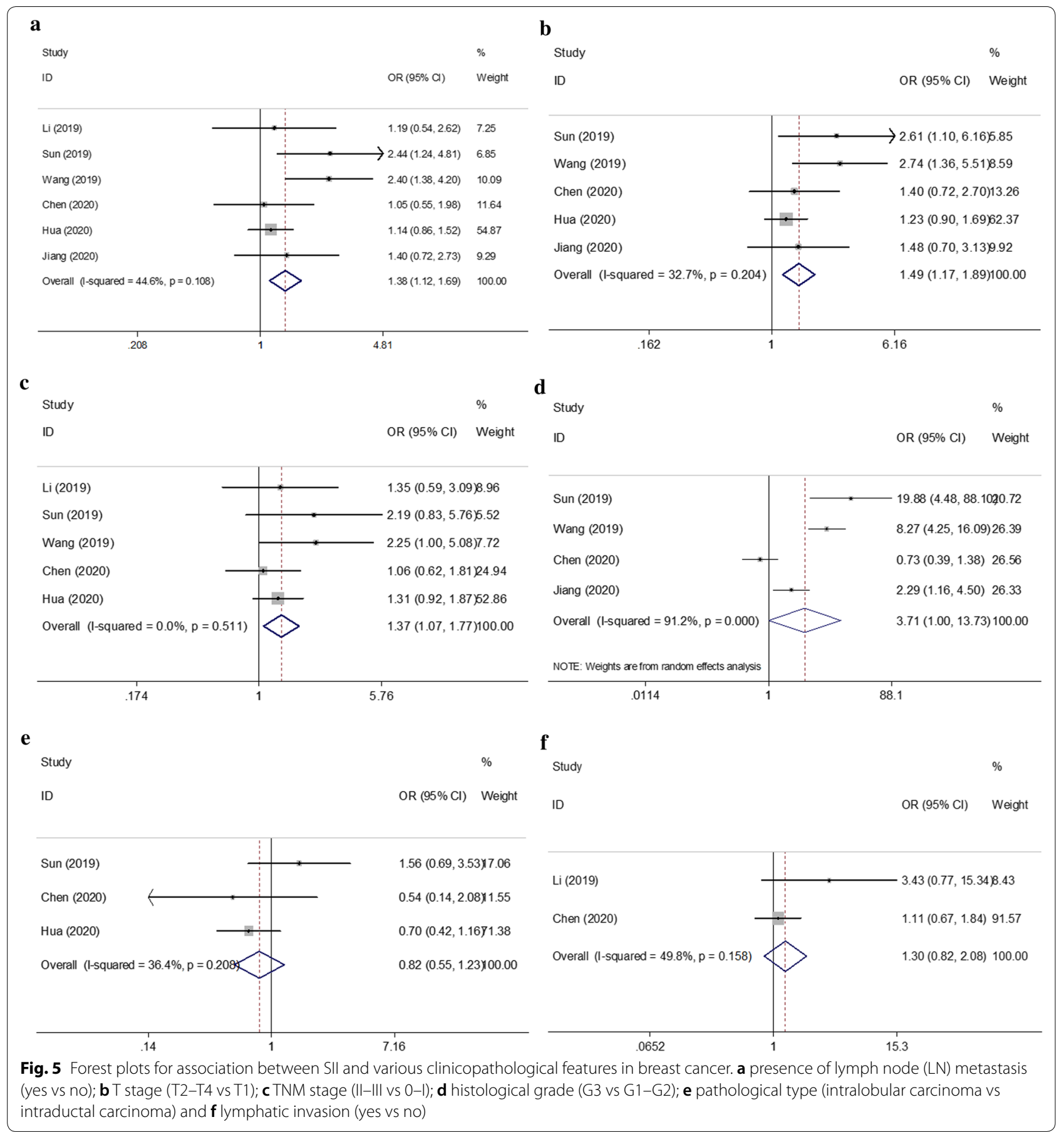


Table 3 Relationship between SII and clinicopathological variables in breast cancer

\begin{tabular}{|c|c|c|c|c|c|c|c|}
\hline \multirow[t]{2}{*}{ Clinicopathological features } & \multirow{2}{*}{$\begin{array}{l}\text { No. } \\
\text { of studies }\end{array}$} & \multirow[t]{2}{*}{ No. of patients } & \multirow[t]{2}{*}{ OR $(95 \% \mathrm{CI})$} & \multirow[t]{2}{*}{$\mathbf{p}$} & \multirow[t]{2}{*}{ Effects model } & \multicolumn{2}{|c|}{ Heterogeneity } \\
\hline & & & & & & $I^{2}(\%)$ & $\mathbf{p}$ \\
\hline LN metastasis (yes vs no) & 6 & 1966 & $1.38(1.12-1.69)$ & 0.002 & Fixed & 44.6 & 0.108 \\
\hline T stage (T2-T4 vs T1) & 5 & 1805 & $1.49(1.17-1.89)$ & 0.001 & Fixed & 32.7 & 0.204 \\
\hline TNM stage (II-III vs 0-I) & 5 & 1819 & $1.37(1.07-1.77)$ & 0.014 & Fixed & 0 & 0.511 \\
\hline Histological grade (G3 vs G1-G2) & 4 & 779 & $3.71(1.00-13.73)$ & 0.049 & Random & 91.2 & $<0.001$ \\
\hline Pathological type (ILC vs IDC) & 3 & 1443 & $0.82(0.55-1.23)$ & 0.345 & Fixed & 36.4 & 0.208 \\
\hline Lymphatic invasion (yes vs no) & 2 & 423 & $1.30(0.82-2.08)$ & 0.266 & Fixed & 49.8 & 0.158 \\
\hline
\end{tabular}

OR odds ratio, $G$ grade, ILC intralobular carcinoma, IDC intraductal carcinoma

SII was not uniform among the studies, which may have introduced a selection bias in the meta-analysis.

\section{Conclusions}

In summary, the results of our meta-analysis suggest that an elevated SII predicts poor survival outcomes and is associated with clinicopathological features that indicate tumor progression of breast cancer. However, owing to the several limitations, more prospective studies including patients with diverse ethnicities are needed to confirm our results. 

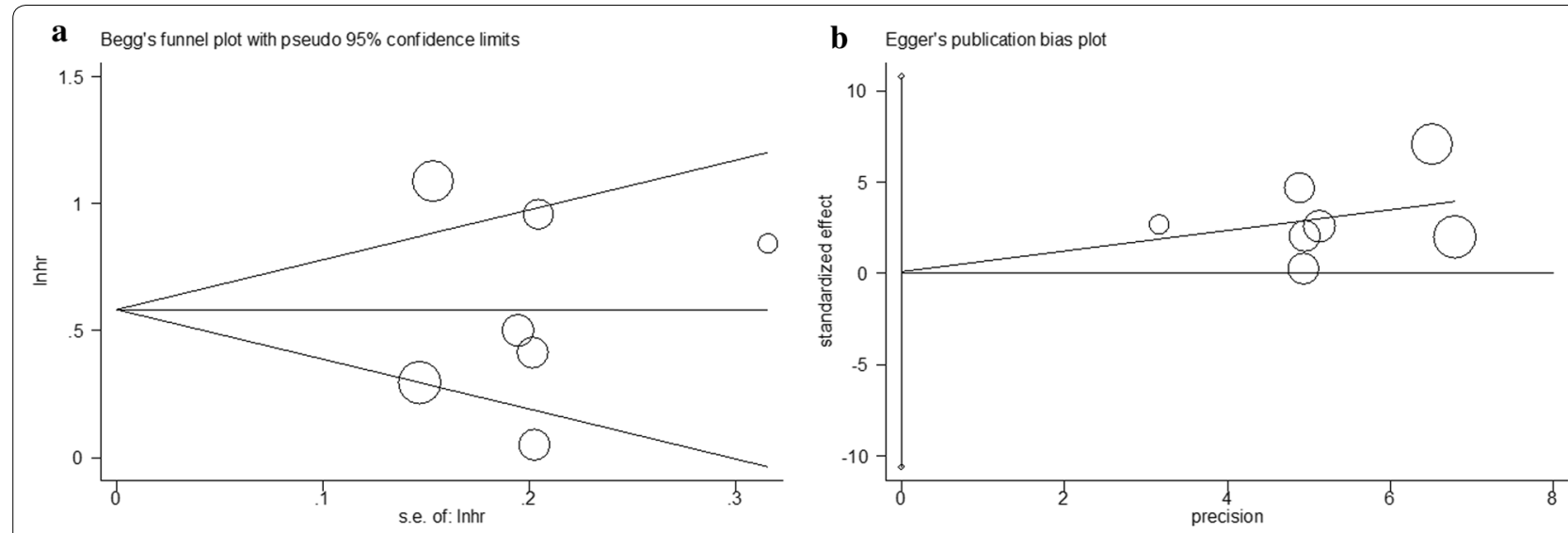

C Begg's funnel plot with pseudo $95 \%$ confidence limits

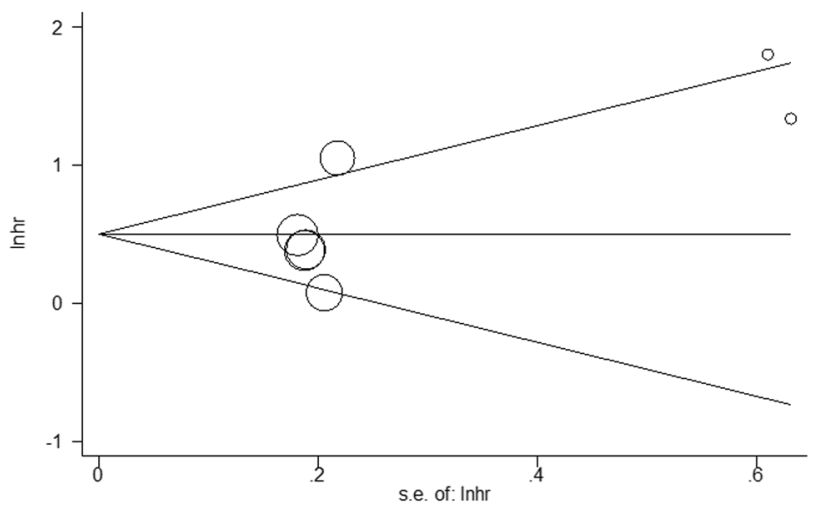

d Egger's publication bias plot

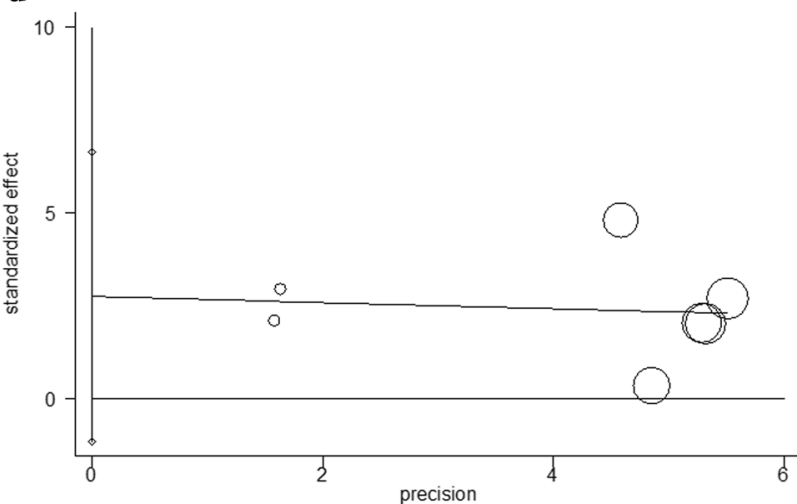

e Begg's funnel plot with pseudo $95 \%$ confidence limits
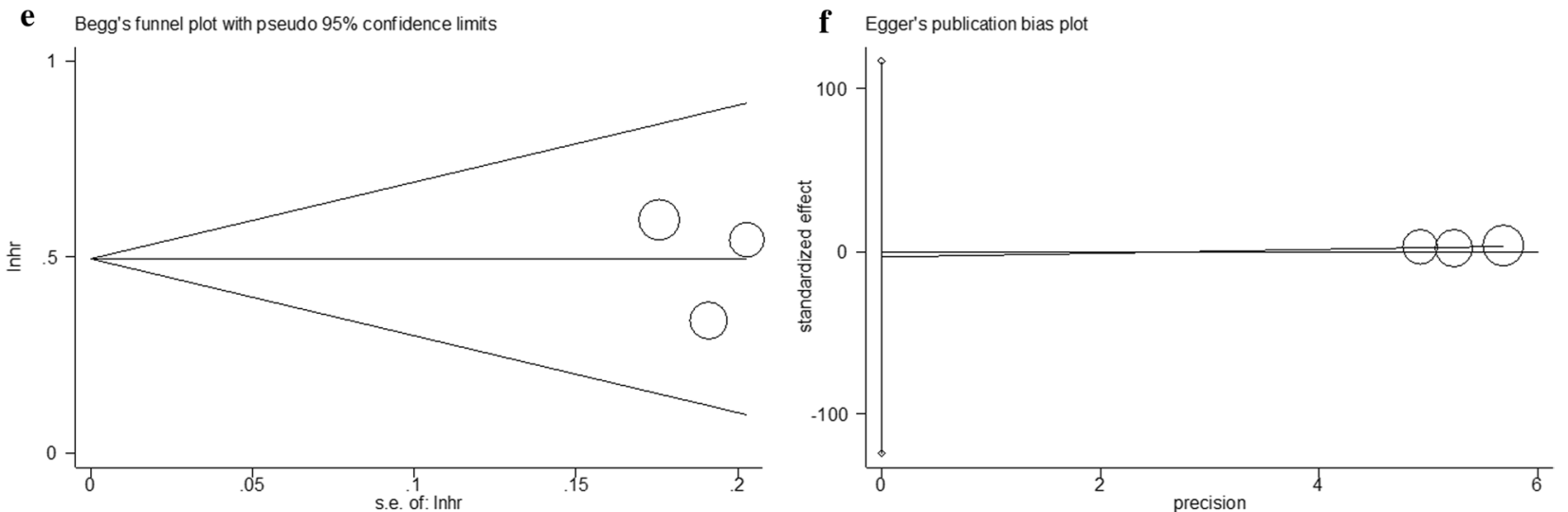

Fig. 6 Begg's funnel plot and Egger's test for the assessment of publication bias in the meta-analysis. a Begg's test for OS; b Egger's test for OS; $\mathbf{c}$ Begg's test for DFS/RFS; $\mathbf{d}$ Egger's test for DFS/RFS; e Begg's test for DMFS; and $\mathbf{f}$ Egger's test for DMFS

\section{Abbreviations}

SIl: Systemic immune-inflammation index; HR: Hazard ratio; Cl: Confidence interval; OS: Overall survival; DFS: Disease-free survival; RFS: Recurrence-free survival; DMFS: Distant metastasis-free survival; NLR: Neutrophil-lymphocyte ratio; PLR: Platelet-lymphocyte ratio; CAR: C-reactive protein/albumin ratio; PRISMA: Preferred Reporting Items for Systematic Reviews and Meta-Analyses Statement; NOS: Newcastle-Ottawa quality assessment scale; OR: Odds ratio; TNBC: Triple-negative breast cancer; HER2: Human epidermal growth factor receptor-2; ILC: Intralobular carcinoma; IDC: Intraductal carcinoma; IL-6: Interleukin-6; PFS: Progression-free survival; CSS: Cancer-specific survival.

\section{Acknowledgements}

Not applicable.

\section{Authors' contributions}

$Y Z$ and $Y S$ wrote the paper by analyzing the above data; $Y Z$ and $Q Z$ collected and draw out data. YS and QZ conducted quality assessment. YZ and YS designed this study. All authors accepted the eventual manuscript. All authors read and approved the final manuscript.

\section{Funding}

None. 


\section{Availability of data and materials}

The datasets analyzed during the current study are available from the corresponding author on reasonable request.

\section{Ethics approval and consent to participate}

Not applicable.

\section{Consent for publication}

Not applicable.

\section{Competing interests}

The authors declare that they have no competing interests.

Received: 12 March 2020 Accepted: 28 May 2020

Published online: 09 June 2020

\section{References}

1. Bray F, Ferlay J, Soerjomataram I, Siegel RL, Torre LA, Jemal A. Global cancer statistics 2018: GLOBOCAN estimates of incidence and mortality worldwide for 36 cancers in 185 countries. CA Cancer J Clin. 2018;68(6):394-424.

2. Harbeck N, Gnant M. Breast Cancer. Lancet. 2017:389(10074):1134-50.

3. Gradishar WJ, Anderson BO, Balassanian R, Blair SL, Burstein HJ, Cyr A, Elias AD, Farrar WB, Forero A, Giordano SH, et al. Breast Cancer, Version 4.2017 Clinical Practice Guidelines in Oncology. J Natl Compr Canc Netw. 2018;16(3):310-20.

4. Fridman WH, Zitvogel L, Sautes-Fridman C, Kroemer G. The immune contexture in cancer prognosis and treatment. Nat Rev Clin Oncol. 2017:14(12):717-34.

5. Zhang K, Hua YQ, Wang D, Chen LY, Wu CJ, Chen Z, Liu LM, Chen H. Systemic immune-inflammation index predicts prognosis of patients with advanced pancreatic cancer. J Transl Med. 2019;17:30.

6. Zhang WT, Wang RL, Ma WC, Wu Y, Maskey N, Guo YD, Liu J, Mao SY, Zhang JF, Yao XD, et al. Systemic immune-inflammation index predicts prognosis of bladder cancer patients after radical cystectomy. Annals of Translational Medicine. 2019;20(23):6212-22.

7. Murthy P, Zenati MS, Al Abbas Al, Rieser CJ, Bahary N, Lotze MT, Zeh HJ 3rd, Zureikat AH, Boone BA. Prognostic Value of the Systemic ImmuneInflammation Index (SII) after neoadjuvant therapy for patients with resected pancreatic cancer. Ann Surg Oncol. 2020;27(3):898-906.

8. Wang C, Jin S, Xu S, Cao S. High Systemic Immune-Inflammation Index (SII) represents an unfavorable prognostic factor for small cell lung cancer treated with etoposide and platinum-based chemotherapy. Lung. 2020;198(2):405-14.

9. De Giorgi U, Mego M, Scarpi E, Giordano A, Giuliano M, Valero V, Alvarez RH, Ueno NT, Cristofanilli M, Reuben JM. Association between circulating tumor cells and peripheral blood monocytes in metastatic breast cancer. Ther Adv Med Oncol. 2019;11:1758835919866065.

10. Li QX, Shi DJ, Zhang LX, Wang DM, Zhao J, Wang T, Deng XN, Fan XY. Association of body mass and systemic immune-inflammation indices with endocrine therapy resistance in luminal breast cancers. J Int Med Res. 2019;47(5):1936-47.

11. Liu JX, Shi ZZ, Bai YS, Liu L, Cheng KL. Prognostic significance of systemic immune-inflammation index in triple-negative breast cancer. Cancer Manag Res. 2019;11:4471-80.

12. Sun Y, Li WQ, Li AJ, Su HC, Yue JB, Yu JM. Increased systemic immuneinflammation index independently predicts poor survival for hormone receptor-negative, HER2-positive breast cancer patients. Cancer Manag Res. 2019;11:3153-62.

13. Wang P, Yue W, Li WY, Luo YQ, Li ZK, Shao Y, He ZZ. Systemic immuneinflammation index and ultrasonographic classification of breast imaging-reporting and data system predict outcomes of triple-negative breast cancer. Cancer Manag Res. 2019;11:813-9.

14. Chen L, Kong X, Wang Z, Wang X, Fang Y, Wang J. Pre-treatment systemic immune-inflammation index is a useful prognostic indicator in patients with breast cancer undergoing neoadjuvant chemotherapy. J Cell Mol Med. 2020;24(5):2993-3021.
15. Jiang L, Fang JJ, Ding JH. High systemic immune-inflammation index predicts poor survival in patients with human epidermal growth factor receptor-2 positive breast cancer receiving adjuvant trastuzumab. Cancer Manag Res. 2020;12:475-84.

16. Hua X, Long ZQ, Zhang YL, Wen W, Guo L, Xia W, Zhang WW, Lin HX. Prognostic value of preoperative systemic immune-inflammation index in breast cancer: a propensity score-matching study. Front Oncol. 2020;10:580.

17. Moher D, Liberati A, Tetzlaff J, Altman DG, Grp P. Preferred reporting items for systematic reviews and meta-analyses: the PRISMA statement. J Clin Epidemiol. 2009;62(10):1006-12.

18. Stang A. Critical evaluation of the Newcastle-Ottawa scale for the assessment of the quality of nonrandomized studies in meta-analyses. Eur J Epidemiol. 2010;25(9):603-5.

19. Cochran W. The combination of estimates from different experiments. Biometrics. 1954;10:101-29.

20. Higgins JPT, Thompson SG. Quantifying heterogeneity in a meta-analysis. Stat Med. 2002;21(11):1539-58.

21. Begg CB, Mazumdar M. Operating characteristics of a rank correlation test for publication bias. Biometrics. 1994;50(4):1088-101.

22. Egger M, Smith GD, Schneider M, Minder C. Bias in meta-analysis detected by a simple, graphical test. Br Med J. 1997;315(7109):629-34.

23. De Giorgi U, Mego M, Scarpi E, Giordano A, Giuliano M, Valero V, Alvarez RH, Ueno NT, Cristofanilli M, Reuben JM: Correlation of circulating tumor cells (CTCS) with peripheral blood leukocytes to predict outcome in metastatic breast cancer (MBC). J Clin Oncol. 2016; 34.

24. Merloni F, Pistelli M, Cantini L, Della Mora A, Bastianelli L, De Lisa M, Burattini M, Maccaroni E, Ballatore Z, Savini A, et al. Role of inflammation parameters in locally advanced breast cancer: the debate is still open. Ann Oncol. 2017;28:37.

25. van der Willik KD, Koppelmans V, Hauptmann M, Compter A, Ikram MA, Schagen SB. Inflammation markers and cognitive performance in breast cancer survivors 20 years after completion of chemotherapy: a cohort study. Breast Cancer Res. 2018;20(1):135.

26. Fest J, Ruiter R, Mulder M, Groot Koerkamp B, Ikram MA, Stricker BH, van Eijck CHJ. The systemic immune-inflammation index is associated with an increased risk of incident cancer-a population-based cohort study. Int J Cancer. 2020;146(3):692-8.

27. Miklikova S, Minarik G, Sedlackova T, Plava J, Cihova M, Jurisova S, Kalavska K, Karaba M, Benca J, Smolkova B, et al. Inflammation-Based Scores Increase the Prognostic Value of Circulating Tumor Cells in Primary Breast Cancer. Cancers (Basel). 2020;12:5.

28. Gao YB, Guo W, Cai SH, Zhang F, Shao F, Zhang GC, Liu TJ, Tan FW, Li $\mathrm{N}$, Xue $\mathrm{Q}$, et al. Systemic immune-inflammation index (SII) is useful to predict survival outcomes in patients with surgically resected esophageal squamous cell carcinoma. J Cancer. 2019;10(14):3188-96.

29. Huang HP, Liu Q, Zhu LX, Zhang Y, Lu XJ, Wu YW, Liu L. Prognostic value of preoperative systemic immune-inflammation index in patients with cervical cancer. Sci Rep. 2019;9:3284

30. Huang $X, H u H Z$, Zhang WY, Shao ZW. Prognostic value of prognostic nutritional index and systemic immune-inflammation index in patients with osteosarcoma. J Cell Physiol. 2019;234(10):18408-14.

31. Man YN, Chen YF. Systemic immune-inflammation index, serum albumin, and fibrinogen impact prognosis in castration-resistant prostate cancer patients treated with first-line docetaxel. Int Urol Nephrol. 2019;51(12):2189-99.

32. Mirili C, Paydas S, Kapukaya TK, Yilmaz A. Systemic immune-inflammation index predicting survival outcome in patients with classical Hodgkin lymphoma. Biomark Med. 2019;13(18):1565-75.

33. Nie D, Gong H, Mao XG, Li ZY. Systemic immune-inflammation index predicts prognosis in patients with epithelial ovarian cancer: a retrospective study. Gynecol Oncol. 2019;152(2):259-64.

34. Wang DY, Guo D, Shi F, Zhu Y, Li AJ, Kong L, Teng FF, Yu JM. The predictive effect of the systemic immune-inflammation index for patients with small-cell lung cancer. Future Oncol. 2019;15(29):3367-79.

35. Tan KW, Chong SZ, Wong FH, Evrard M, Tan SM, Keeble J, Kemeny DM, $\mathrm{Ng} \mathrm{LG}$, Abastado JP, Angeli V. Neutrophils contribute to inflammatory lymphangiogenesis by increasing VEGF-A bioavailability and secreting VEGF-D. Blood. 2013;122(22):3666-77. 
36. Nieswandt B, Hafner M, Echtenacher B, Mannel DN. Lysis of tumor cells by natural killer cells in mice is impeded by platelets. Cancer Res. 1999;59(6):1295-300.

37. Gay LJ, Felding-Habermann B. Contribution of platelets to tumour metastasis. Nat Rev Cancer. 2011;11(2):123-34.

38. Dunn GP, Old LJ, Schreiber RD. The immunobiology of cancer immunosurveillance and immunoediting. Immunity. 2004;21(2):137-48.

39. Chen L, Zhang F, Sheng XG, Zhang SQ. Decreased pretreatment lymphocyte/monocyte ratio is associated with poor prognosis in stage Ib1-Ila cervical cancer patients who undergo radical surgery. Onco Targets Ther. 2015;8:1355-62.

40. Zhong JH, Huang DH, Chen ZY. Prognostic role of systemic immuneinflammation index in solid tumors: a systematic review and meta-analysis. Oncotarget. 2017;8(43):75381-8.
41. Yang R, Chang Q, Meng X, Gao N, Wang W. Prognostic value of Systemic immune-inflammation index in cancer: a meta-analysis. J Cancer. 2018;9(18):3295-302.

42. Wang Y, Li Y, Chen P, Xu W, Wu Y, Che G. Prognostic value of the pretreat ment systemic immune-inflammation index (SII) in patients with nonsmall cell lung cancer: a meta-analysis. Ann Transl Med. 2019;7(18):433.

43. Wang B, Huang Y, Lin T. Prognostic impact of elevated pre-treatment systemic immune-inflammation index (SII) in hepatocellular carcinoma: a meta-analysis. Medicine (Baltimore). 2020;99(1):e18571.

\section{Publisher's Note}

Springer Nature remains neutral with regard to jurisdictional claims in published maps and institutional affiliations.
Ready to submit your research? Choose BMC and benefit from:

- fast, convenient online submission

- thorough peer review by experienced researchers in your field

- rapid publication on acceptance

- support for research data, including large and complex data types

- gold Open Access which fosters wider collaboration and increased citations

- maximum visibility for your research: over $100 \mathrm{M}$ website views per year

At BMC, research is always in progress.

Learn more biomedcentral.com/submissions 